Abstracta Iranica Iranica

Revue bibliographique pour le domaine irano-aryen

Volume 32-33 | 2013

Comptes rendus des publications de 2009-2010

\title{
Michael Jursa. Aspects of the Economic History of Babylonia in the First Millennium BC
}

\section{Rémy Boucharlat}

\section{(2) OpenEdition}

1 Journals

Édition électronique

URL : http://journals.openedition.org/abstractairanica/40340

DOI : 10.4000/abstractairanica.40340

ISSN : 1961-960X

\section{Éditeur :}

CNRS (UMR 7528 Mondes iraniens et indiens), Éditions de l'IFRI

\section{Édition imprimée}

Date de publication : 1 décembre 2013

ISSN : 0240-8910

\section{Référence électronique}

Rémy Boucharlat, « Michael Jursa. Aspects of the Economic History of Babylonia in the First Millennium $B C »$, Abstracta Iranica [En ligne], Volume 32-33 | 2013, document 83, mis en ligne le 01 juillet 2016 , consulté le 10 décembre 2020. URL : http://journals.openedition.org/abstractairanica/40340 ; DOI : https://doi.org/10.4000/abstractairanica.40340

Ce document a été généré automatiquement le 10 décembre 2020.

Tous droits réservés 


\title{
Michael Jursa. Aspects of the Economic History of Babylonia in the First Millennium BC
}

\author{
Rémy Boucharlat
}

\section{RÉFÉRENCE}

Michael Jursa. Aspects of the Economic History of Babylonia in the First Millennium BC. Münster, Ugarit-Verlag, 2010, XVIII-897 p. (AOAT 377)

1 C'est le quatrième volume d'une série consacrée à « Aspects of the Economic History of Babylonia in the First Millennium BC». Economy, Geography, Economic Mentalities, Agriculture, the Use of Money and the Problem of Economic Growth. Historien et assyriologue du $1^{\mathrm{er}}$ mill., l'A. traite de ce qu'il appelle "the long sixth century », qui s'étend du déclin de l'empire assyrien vers la fin $\mathrm{du} \mathrm{VII}^{\mathrm{e}} \mathrm{s}$. et la révolte babylonienne contre Xerxès en 484. L'A. a dirigé de 2002 à 2009 un programme START qui portait le titre de l'ouvrage, avec le concours d'une équipe de quatre spécialistes, il a su produire très rapidement les résultats.

2 M.J. livre une masse d'informations à partir d'archives non royales (il n'y a pas d'archives royales en Mésopotamie achéménide). Ce sont celles de temples et de familles de marchands. Pour donner un ordre de grandeur, deux temples, l'Eanna d'Uruk et l'Ebabbar de Sippar ont livré respectivement 8000 et 35000 tablettes cunéiformes, tandis que deux lots d'archives privées celles des Egibi de Babylone et celles des Murašu de Nippur comptent 1700 et 750 tablettes. +Cette documentation permet à l'A. de traiter cinq chapitres : 1 / Une longue et pénétrante introduction de soixante pages, dans laquelle l'A. donne le cadre historique de la période, une importante histoire de la recherche assyriologique, les méthodes des historiens de la région et leur évolution récente de celle-ci. 2/ Routes et communication internes dans la Babylonie, échanges de produits. 3/Stratégies économiques et types 
d'investissement (contrats sur des maisons, palmeraies, terres cultivables, prêts, taxes, esclaves, animaux, etc.). 4/ Agriculture et maîtrise du paysage ; évolution durant la période achéménide. 5/ Le métal argent, le monnayage d'argent (sous forme de morceaux ou barres mais non de pièces). 6 / Conclusion générale et questions pour de futures recherches.

3 Cet ouvrage est une contribution en profondeur de cette inépuisable mine d'information que sont les tablettes inscrites de Mésopotamie ; des dizaines de milliers, conservées dans différents musées, attendent encore d'être déchiffrées, publiées et analysées pour reconstruire l'histoire d'une région si importante de l'empire achéménide.

\section{AUTEURS}

\section{RÉMY BOUCHARLAT}

CNRS, Lyon 